\title{
Application of Resistivity Method for Mining Tailings Site Selection in Karst Regions
}

\author{
Mosaad Ali1,2, ${ }^{1,}$, Shulin Sun $^{1}$, Wei Qian ${ }^{1,3}$, Abdou Dodo Bohari ${ }^{1}$,Dusabemariya Claire ${ }^{1}$, and \\ Yan Zhang ${ }^{1}$ \\ ${ }^{1}$ School of Earth Science and Engineering, Hohai University, P.R. China \\ ${ }^{2}$ Department of Mining and Metallurgy Eng., Faculty of Eng., Assiut University, Egypt \\ ${ }^{3}$ Geoserve Logging \&Tomography, Canada
}

\begin{abstract}
Disposal of mining wastes (tailings) is one of the most severe issues related to groundwater contamination. Therefore, a properly selected disposal site helps to prevent the leakage of dissolved materials in the tailings to groundwater, especially in the karstic area. Where the karstic environment is one of the challenges facing groundwater environmental and engineering issues, for instance, groundwater exploration, vulnerability assessment, and hazard estimation. In this study, the resistivity method with a high-resolution surface data survey was carried out to investigate the pond location selection for mining tailings disposal at El Mochito mine site, northwest Honduras. The results of the two-dimensional (2-D) inversion for sixteen surveyed lines revealed that many low resistivity zones. These zones are related to water/clay-bearing zones that are structurally weak. From lines $8-12$, the limestone underneath the surface is the most compact, and this is the best location in the survey area for tailings pond construction. The resistivity method has provided insight into the subsurface information and locating hydraulically conductive zones, so it can be useful for selecting the site of mining tailings.
\end{abstract}

Keywords. Resistivity, Karst, Tailings, Groundwater, Inversion

\section{Introduction}

Waste disposal locations can seriously affect groundwater contamination, and therefore their sites must be precisely planned and monitored [1, 2]. A total load of pollutants on the environment depends on the quality and quantity of a fluid that seeps through the disposal location and reaches groundwater [3]. The mining tailings if disposed of without a clear plan of the selection of a suitable site for these tailings. The environmental consequences of unplanned disposal locations are often a severe source of groundwater contamination especially in a karstic area [4]. Karst, a cavity formed by limestone or carbonate rocks that have been eroded by dissolution, creating voids, sinkholes, fissures, and other characteristic cracks $[5,6]$. The karst formation is one of the challenges facing groundwater environmental and engineering issues, for instance, groundwater exploration, vulnerability assessment, and hazard estimation [7-9].

*Corresponding author: mossad_ali2000@aun.edu.eg 
Traditional techniques of predicting karstic zones, like probe drilling, are hampered by asymmetric spatial distribution, geological structures and variable sizes for the topographic features $[10,11]$. The resistivity method is a geophysical method that based on the changing in resistivity of subsurface material properties $[12,13]$. The variation in material properties between rocks of limestone and karstic zones causes a noted changing in resistivity values that can create a map of the resistivity distribution of subsurface features $[14,15]$. For that the resistivity method has become a powerful method for water and environmental investigation issues [16-18]. The resistivity method is frequently utilized as a geophysical survey method in several applications in different fields, for instance, minerals exploration, hydrological engineering, geotechnical engineering, and environmental investigations [19-23]. However, there is a paucity of published studies on environmental assessment mining resistivity method applications, especially in the selection of the optimum location of a mining tailing disposal.

The purpose of this study is to prove the ability of the resistivity method in the selection of an appropriate location of a mining tailing disposal that does not contain karstic zones or less affected at the El Mochito mine area, north-western Honduras. The area consists of an underground mine of sulfide deposits (lead-zinc-silver) and a concentrator to separate the concentrate (lead and zinc) and tailing (a dense fluid containing gangue materials mixed with flotation solutions) [24, 25].

In this study, the resistivity multi-electrodes surface method using a high-resolution data survey was carried out to investigate the pond location selection for mining tailings disposal at El Mochito mine area.

\section{The Site and geological information}

The El Mochito mine area is located at the southwestern edge of the Sula graben (Sula Valley) on the western end of the Honduras Depression in the Central of Honduras, (Lat, Lon: 14.868727, -88.077564) in Figure (1-a), from which the "Upper Jurassic" to "Quaternary" units determine the outcropping stratigraphy extent [26, 27]. The mine area is hosted in an around a 6000-meter-thick sedimentary basin of the Mesozoic sediments that cross the country in an approximately east-west direction [27]. These stratigraphies are underlain by "Paleozoic" metamorphic rocks and overlain by "Tertiary" volcanic rocks. A simplified stratigraphic distribution for the mine area is as shown in Figure (1-b). The mineralization at the mine area occurs as both chimney and manto skarn deposits in "Lower Cretaceous" limestones [28].

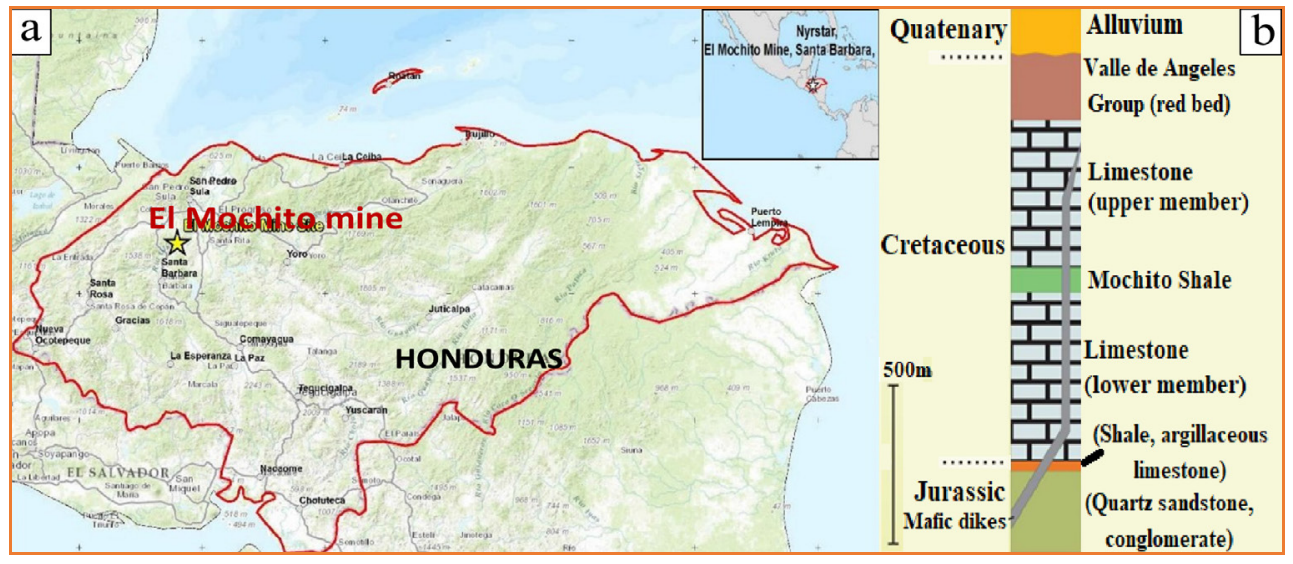

Fig. 1. The site information; a) site map, b) a simplified stratigraphic column [25]. 


\section{Methodology}

The geophysical survey process was carried out using the EarthProbe, the automatic multielectrodes, and the high-resolution system in Figure (2) [29]. The system can be configured to collect high-resolution surface and borehole DC (direct current) resistivity data. For this survey, the resistivity data were collected using the high-resolution a 2-D surface DC surveying technique as shown in Figure (3). Only voltage and current were measured, resulting in a calculation of apparent resistivity. In this study, conventional electrode nomenclature is used, whereby " $\mathrm{A}$ " denotes the positive current electrode, " $\mathrm{B}$ " the negative current electrode, " $\mathrm{M}$ " the positive potential electrode and " $\mathrm{N}$ " the negative potential electrode [30].

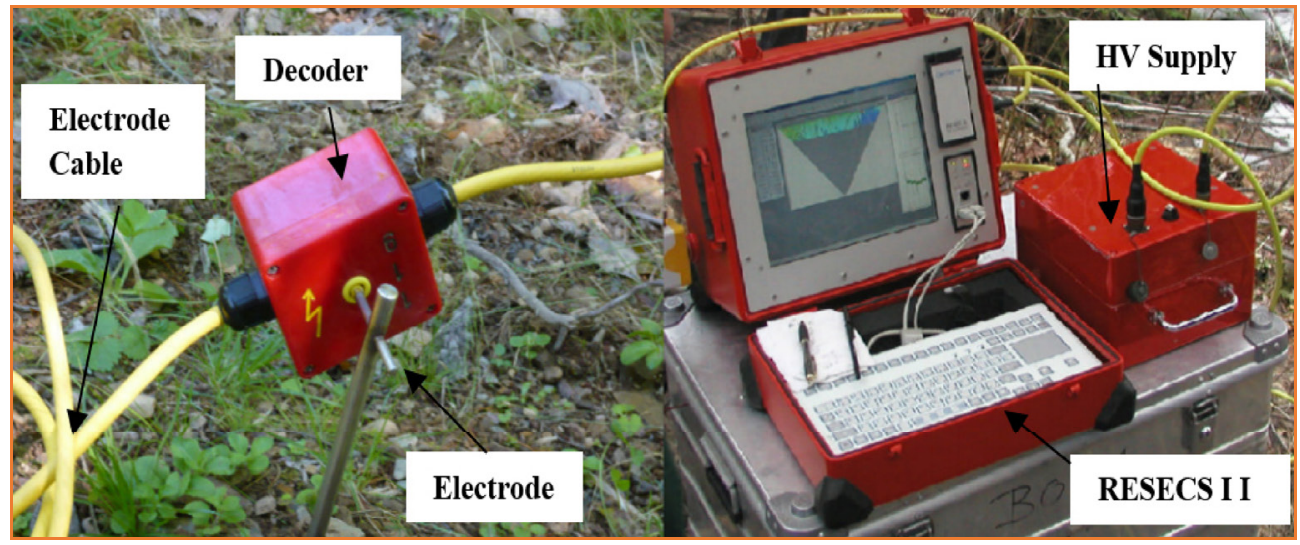

Fig. 2. The Earth Probe system components.

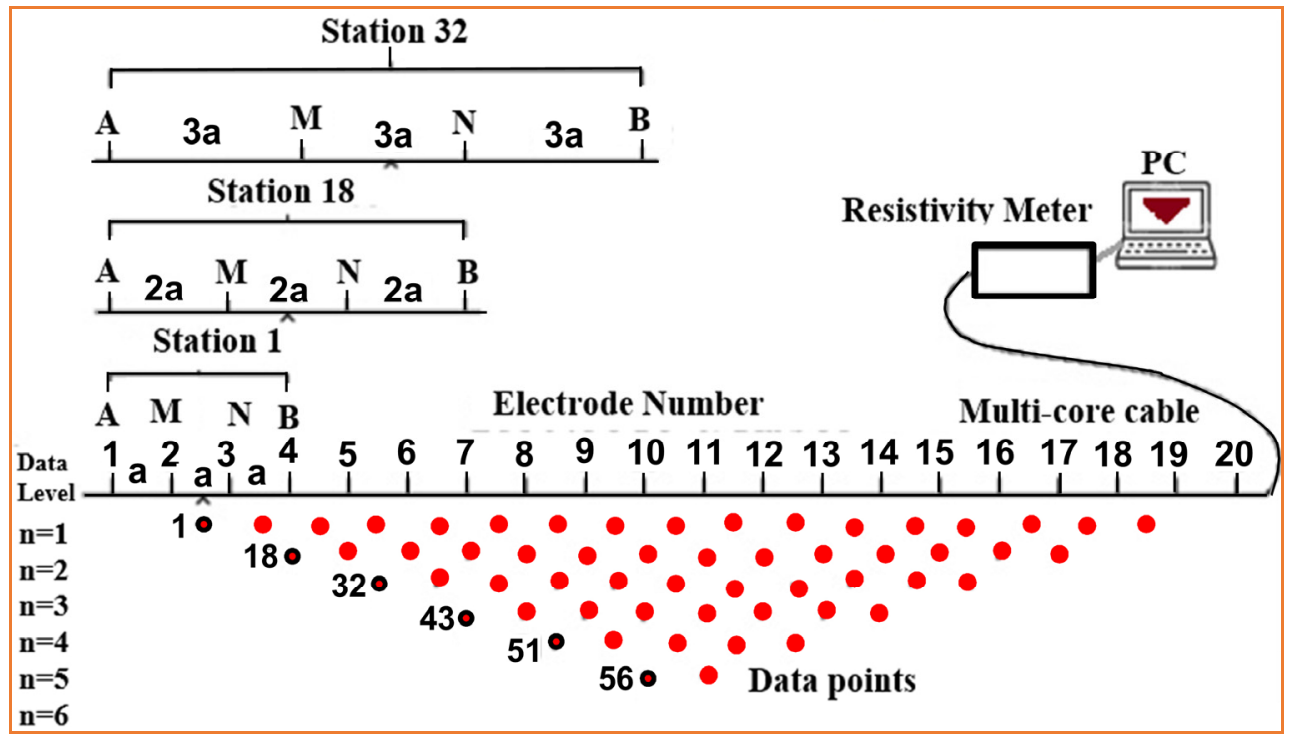

Fig. 3. The arrangement of electrodes and the sequence of 2-D surface measurements using Wenner Alpha array to build up a model (pseudosection) [31].

Lines location and electrodes information are displayed in Figure (4). DC apparent resistivity data were collected along sixteen surface lines spaced $20 \mathrm{~m}$ apart. The electrode 
separation was $2.3 \mathrm{~m}$. GPS data of each electrode were measured by a total station to consider the topographic effect in the inversion process.

The electrode configuration used for this survey was the Wenner-alpha configuration. Stainless steel stakes were used for current electrodes (A-B) as well as for the potential electrodes (M-N). In this array, A-M-N-B is equally spaced, and for each reading, the "aspacing" between all electrodes is incremented by one, as shown in Figure (3).

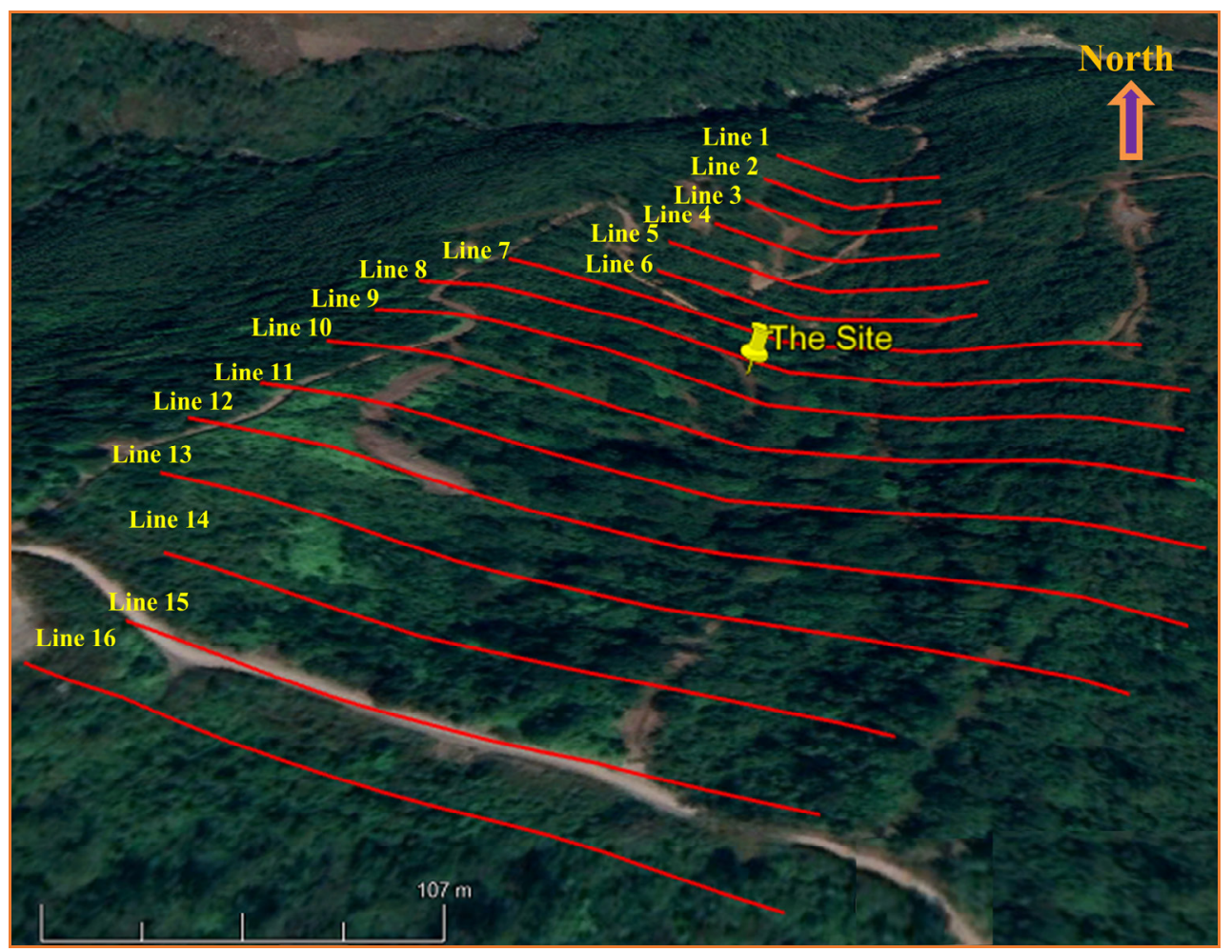

Fig. 4. Location map of the survey Lines.

\section{Results and discussion}

According to the geological evidence and previous research conducted at the El Mochito mine site, this site revealed a strongly jointed (voids) limestone system, and karstic solution cavities were observed in the underground tunnels and boreholes [25, 26, 32, 33]. The underground tunnels are approximately 80 meters below the ground surface, and borehole data indicates the presence of highly weathered limestone residual soil overlying highly fractured and karstified limestone bedrock. The residual soils consist of medium dense sands and gravels with a thickness of up to 10 meters underlying a few meters of soft clayey soil. Several voids were encountered in one borehole at depth within the rock [25, $32,34]$. These voids were partially filled with clay, which may indicate the movement of water. Highly weathered limestone, water-bearing fracture zones, and voids filled with water/clay are low resistivity features.

From the inverted sections are shown in Figure (5) for line 1 to line 4, we can see several highly weathered limestone patches at the surface. At the valley, there is a waterbearing fracture zone that cuts through a relatively compact limestone unit. 


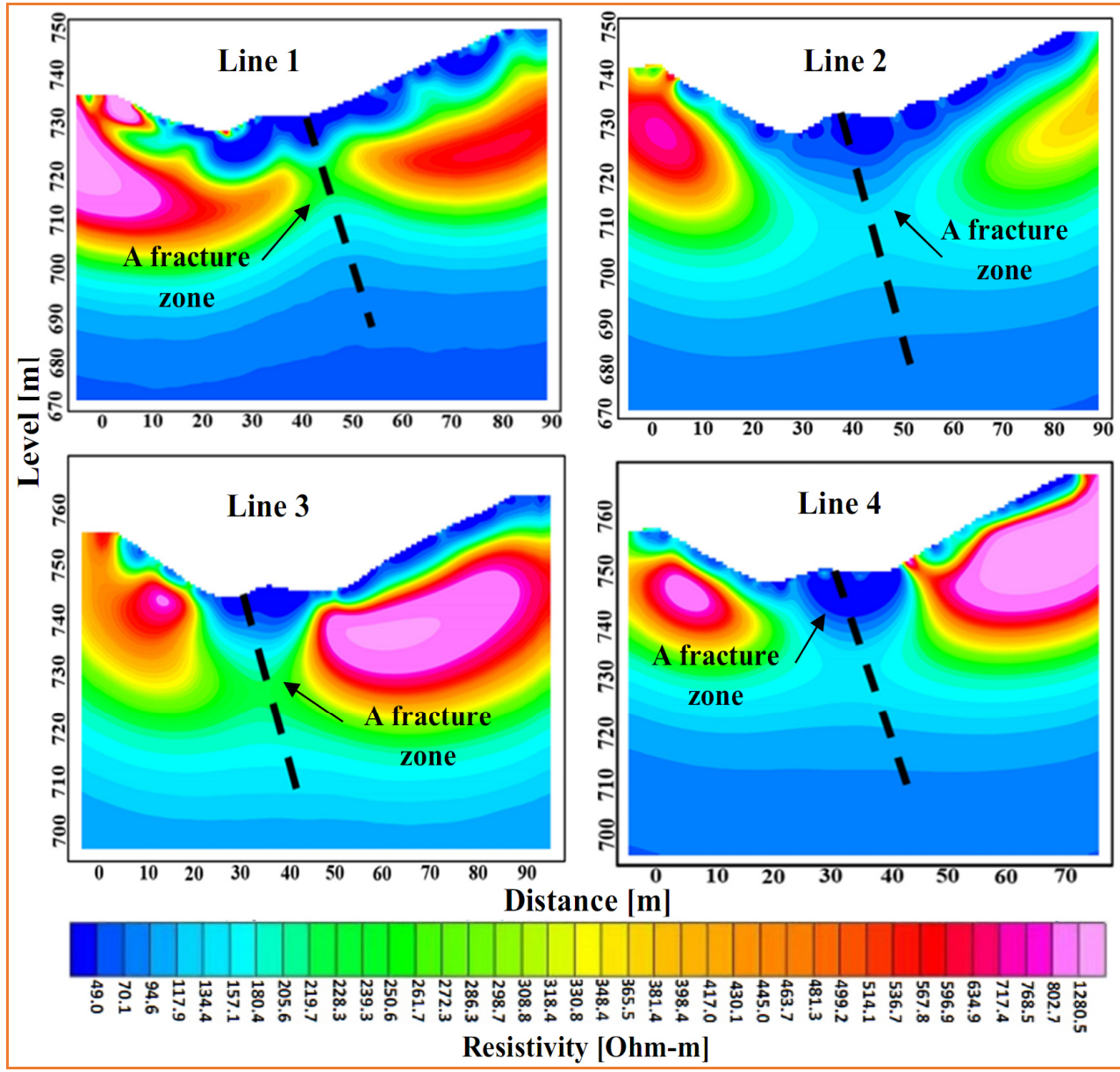

Fig. 5. 2-D inversion of resistivity for Lines 1-4.

The limestone underneath line 5 in Figure (6) looks very compact, except the break at the valley. The limestone underneath line 6 looks very compact, except that there might be a void as marked. A void and a break can be identified underneath line 7 . There is a good chunk of compact limestone underneath line 8 , but at the western end, the limestone seems to have been compromised with fractures and fluid. Most of the limestone underneath lines 9 to 12 is compact. This limestone base for these lines at the valley represents the best structure to hold tailings. 


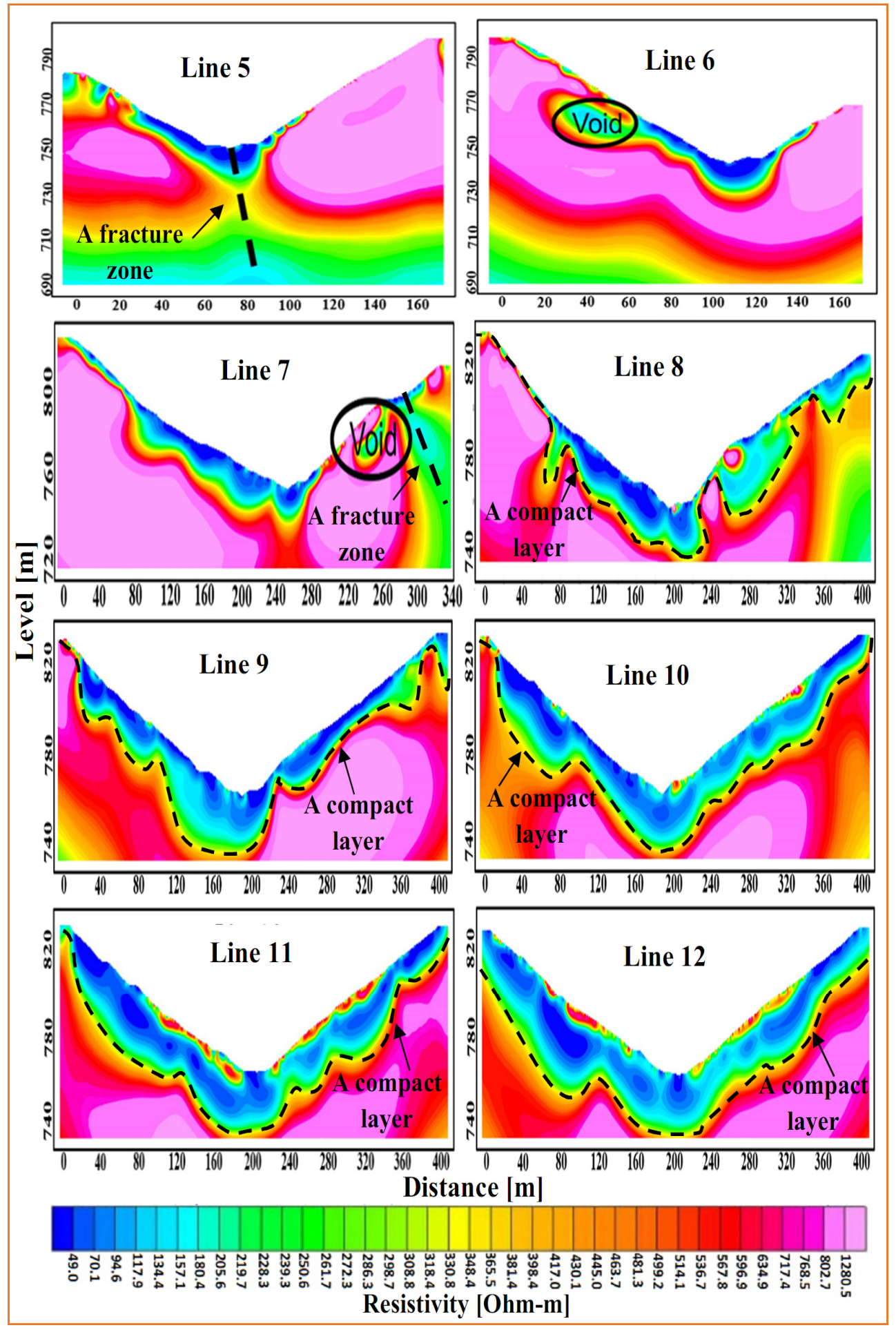

Fig. 6. 2-D inversion of resistivity for Lines 5-12. 
The eastern side of the limestone base starts to show fracturing (low resistivity) underneath the lines 13 and 14 in Figure (7). The limestone underneath the lines 15 and 16 are highly compromised with fractures and water.

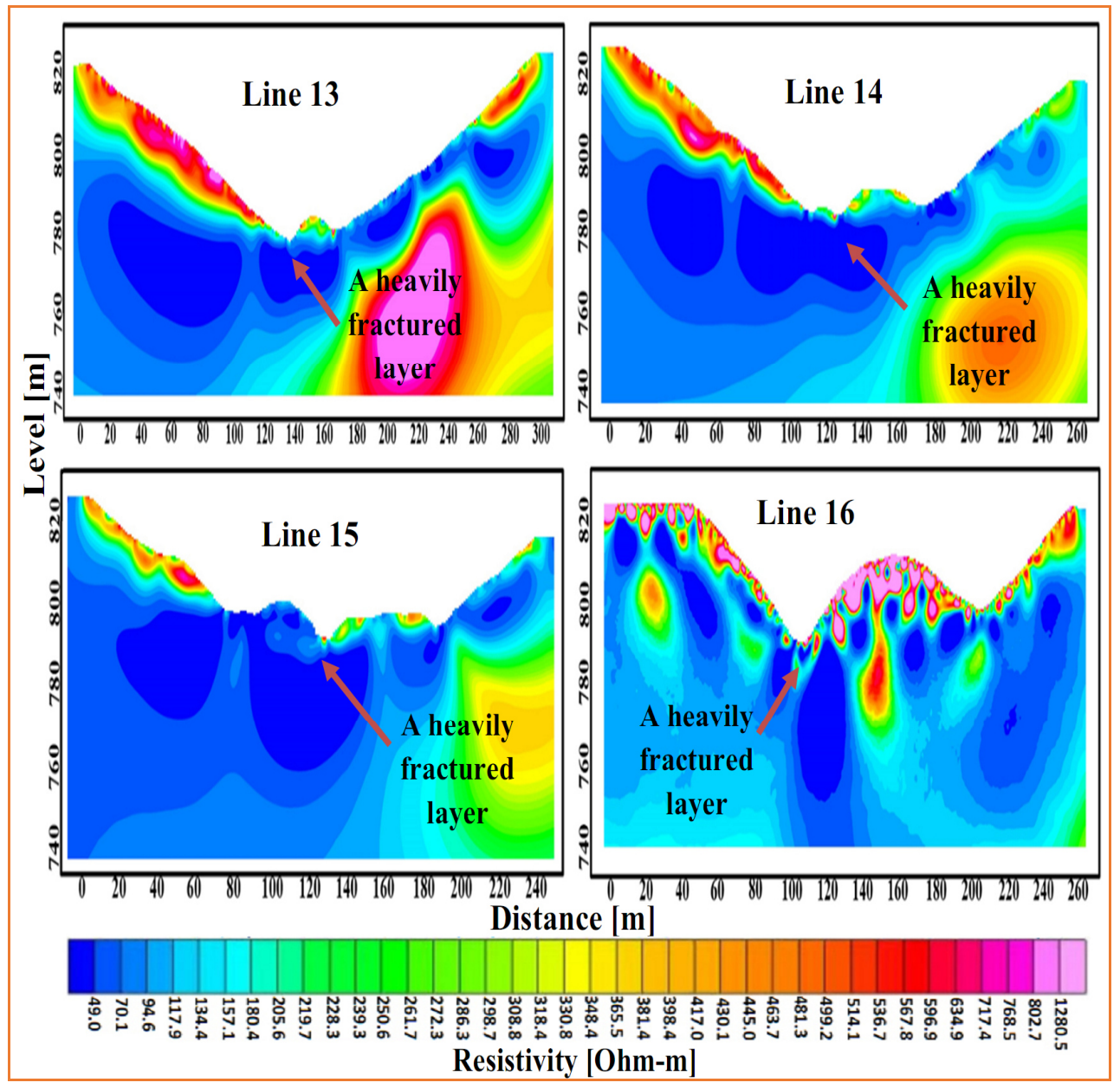

Fig. 7. 2-D inversion of resistivity for Lines 13-16.

\section{Conclusions}

From lines 8-12, the limestone underneath the surface is the most compact and this is the best location in the survey area for tailing pond construction. From lines 1-7, At the valley, there are water-bearing fracture zones and voids that cut through a relatively compact limestone unit. The limestone underneath the lines 13-16 is suffering highly compromised with fractures and water. The resistivity method has provided insight into the subsurface information and locating hydraulically conductive zones, so it can be useful for selecting the location of mining tailings. 


\section{References}

1. M. S. Matias, M. M. da Silva, P. Ferreira, E. Ramalho, A geophysical and hydrogeological study of aquifers contamination by a landfill. J. Appl. Geophys. 32, 155-162 (1994).

2. R. Poudel, Y. Hirai, M. Asari, S. Sakai, Field study of disaster waste management and disposal status of debris after Gorkha Earthquake in Kathmandu, Nepal. $J$. Mater. Cycles Waste Manag., 1-13 (2019).

3. L. Bengtsson, D. Bendz, W. Hogland, H. Rosqvist, M. Åkesson, Water balance for landfills of different age. J. Hydrol. 158, 203-217 (1994).

4. K. Chalikakis, V. Plagnes, R. Guerin, R. Valois, F. P. Bosch, Contribution of geophysical methods to karst-system exploration: an overview. Hydrogeol. J. 19, 1169 (2011).

5. D. Ford, P. D. Williams, Karst hydrogeology and geomorphology. John Wiley \&amp; Sons, (2013).

6. W. B. White, A brief history of karst hydrogeology: contributions of the NSS. $J$. Cave Karst Stud. 69, 13-26 (2007).

7. R. C. Gogu, A. Dassargues, Current trends and future challenges in groundwater vulnerability assessment using overlay and index methods. Environ. Geol. 39, 549559 (2000).

8. M. Bakalowicz, Karst groundwater: a challenge for new resources. Hydrogeol. $J$. 13, 148-160 (2005).

9. S. Foster, R. Hirata, D. Gomes, M. D'Elia, M. Paris, Groundwater quality protection: a guide for water service companies, municipal authorities and environment agencies. The World Bank, (2002).

10. E. Slob, M. Sato, G. Olhoeft, Surface and borehole ground-penetrating-radar developments. Geophysics. 75, 75A103--75A120 (2010).

11. P. Ortoleva, Methods and systems for simulation-enhanced fracture detections in sedimentary basins (2002).

12. M. B. Dobrin, C. H. Savit, Introduction to geophysical prospecting. McGraw-hill New York, 4 (1960).

13. A. Binley, A. Kemna, in Hydrogeophysics. Springer, pp. 129-156 (2005).

14. C. Gélis, A. Revil, M. E. Cushing, D. Jougnot, F. Lemeille, J. Cabrera, A. De Hoyos, M. Rocher, Potential of electrical resistivity tomography to detect fault zones in limestone and argillaceous formations in the experimental platform of Tournemire, France. Pure Appl. Geophys. 167, 1405-1418 (2010).

15. P. Cosenza, A. Ghorbani, N. Florsch, A. Revil, Effects of drying on the lowfrequency electrical properties of Tournemire argillites. Pure Appl. Geophys. 164, 2043-2066 (2007).

16. A. Sirhan, M. Hamidi, P. Andrieux, others, Electrical resistivity tomography, an assessment tool for water resource: Case study of Al-Aroub Basin, West Bank, Palestine. Asian J. Earth Sci. 4, 38-45 (2011).

17. L. D. Slater, D. Lesmes, IP interpretation in environmental investigations. Geophysics. 67, 77-88 (2002).

18. P. Soupios, I. Papadopoulos, M. Kouli, I. Georgaki, F. Vallianatos, E. Kokkinou, Investigation of waste disposal areas using electrical methods: a case study from Chania, Crete, Greece. Environ. Geol. 51, 1249-1261 (2007). 
19. A. K. Greve, R. I. Acworth, B. F. J. Kelly, 3D cross-hole resistivity tomography to monitor water percolation during irrigation on cracking soil. Soil Res. 49, 661-669 (2011).

20. G. W. Leney, Field studies in iron ore geophysics. Min. Geophys. 1, 391 (1966).

21. E. E. Maillot, J. S. Sumner, Electrical properties of porphyry deposits at Ajo, Morenci, and Bisbee, Arizona. Min. Geophys. 1, 273-287 (1966).

22. F. W. Schwartz, G. L. McClymont, Applications of surface resistivity methods. Groundwater. 15, 197-202 (1977).

23. D. W. Urish, The practical application of surface electrical resistivity to detection of ground-water pollution. Groundwater. 21, 144-152 (1983).

24. K. M. Ault, Sulfur and lead isotope study of the El Mochito Zn-Pb-Ag deposit. Econ. Geol. 99, 1223-1231 (2004).

25. V. Éric, M. P. Cullen, D. G. Feasby, "NI 43-101 Technical Report Amended Preliminary Economic Assessment for the Optimization and Expansion of the El Mochito Mine" (2018).

26. R. C. Finch, Mesozoic stratigraphy of central Honduras. Am. Assoc. Pet. Geol. Bull. 65, 1320-1333 (1981).

27. I. M. Samson, A. E. Williams-Jones, K. M. Ault, J. E. Gagnon, B. J. Fryer, Source of fluids forming distal $\mathrm{Zn}-\mathrm{Pb}-\mathrm{Ag}$ skarns: Evidence from laser ablation--inductively coupled plasma--mass spectrometry analysis of fluid inclusions from El Mochito, Honduras. Geology. 36, 947-950 (2008).

28. W. A. Gose, R. C. Finch, Stratigraphic implications of palaeomagnetic data from Honduras. Geophys. J. Int. 108, 855-864 (1992).

29. I. C. C. C. Palich Julie Qian Wei, EarthProbe: Meeting the Challenges of Gold Exploration through High Resolution Borehole and Surface IP. (2007)

30. W. Qian, B. Milkereit, G. McDowell, K. Stevens, S. Halladay, Borehole Resistivity Logging and Tomography for Mineral Exploration. Proc. Explor. 07 Fifth Decenn. Int. Conf. Miner. Explor., 1115-1118 (2007).

31. M. Loke, 2-D and 3-D Electrical Imaging Surveys. Tutorial, 29 (2004).

32. C. G. Cunningham, Earth and water resources and hazards in Central America. US Department of the Interior, Geological Survey, (1984).

33. J. Bundschuh, G. E. Alvarado, Central America, Two Volume Set: Geology, Resources and Hazards. CRC Press, (2012).

34. F. Gutiérrez, M. Parise, J. De Waele, H. Jourde, A review on natural and humaninduced geohazards and impacts in karst. Earth-Science Rev. 138, 61-88 (2014). 